\title{
TECNOLOGIAS SOCIALMENTE ÚTEIS
}

\author{
Bravo Nico, Lurdes Pratas Nico, Daniela Lopes, Vanessa Sampaio, \\ Flávio Lino, Maria Pencas \& Patrícia Ramalho ${ }^{1}$
}

\section{MISSÃO DA SUÃO - ASSOCIAÇÃO DE DESENVOLVIMENTO COMUNITÁRIO}

A Suão - Associação de Desenvolvimento Comunitário constitui-se no ano de 1998, na freguesia de São Miguel de Machede (concelho e distrito de Évora).

Os objetivos da sua fundação desde logo se fundiram com a valorização e construção de de competências nos jovens que mostraram vontade de colaborar num objeto social e educativo de apoio à comunidade. Assim, a par do quadro social com que se depararam no início dos trabalhos, os jovens mobilizaram as suas habilidades ao serviço da comunidade. A instituição assume, como missão, a promoção do desenvolvimento humano, social e económico da comunidade, num contexto sustentável, solidário e participado.

A Suão promove, desde a sua constituição, uma Escola Comunitária. É no seu seio que são pensados e concretizados os projetos.

\section{OS PROJETOS QUE DESENVOLVE}

Os projetos desenvolvidos pela SUÃO caraterizam-se pela presença estruturante da Educação, o diálogo e a cooperação entre as gerações presentes na comunidade e o estímulo constante à qualificação dos mais jovens e à rentabilização local dessa qualificação.

Em seguida, descreveremos alguns dos projetos desenvolvidos na Suão. Estes projetos contam com várias parcerias como: Câmara Municipal de Évora, o Instituto Português do Desporto e da Juventude (IPDJ), Centro Distrital de Évora da Segurança Social, Jornal Regional “Diário do Sul

1 Escola Comunitária de São Miguel de Machede/SUÃO - Associação de Desenvolvimento Comunitário; suao.fazerbem@gmail.com 
(i) Curso de Educação Comunitária - O curso conta, atualmente, com a participação de, aproximadamente, 25 alunos. O curso, coordenado pela Assistente Social Daniela Lopes e pela Psicóloga Patrícia Ramalho, está organizado em várias disciplinas, que aos alunos frequentam, de acordo com os seus interesses e disponibilidade: Alfabetização, Informática, Dinâmicas de Grupo, Expressão Visual e Expressão Físico Motora, incluindo a Ginástica e a Hidroginástica. Este projeto baseia-se em valores como o direito à educação, aprendizagem ao longo da vida e educação para todos. Para que o mesmo seja possível, o Curso de Educação de Adultos tem parcerias como o Instituto Português do Desporto e da Juventude (IPDJ), o Centro Distrital de Évora da Segurança Social e a Universidade Popular Túlio Espanca da Universidade de Évora. Esta atividade desenvolve-se desde 1997, data anterior à constituição da própria instituição. Nesse ano, realizou-se o primeiro curso de alfabetização para um grupo de senhoras.

(ii) Gabinete da Papelada - Este projeto, equivalente à Loja do Cidadão, ajuda os cidadãos de São Miguel de Machede na resolução de assuntos que têm que ser tratados por serviços que se encontram em Évora. O apoio da Suão passa pela mediação e preenchimento de documentos que têm que ser entregues em vários serviços administrativos. Entre vários processos, a Suão trata de assuntos relacionados com questões da vida diária: faturas da luz, consumo de água, telefone, Câmara Municipal, Finanças, Segurança Social, IEFP, Centro de Emprego. Para além disso, o Gabinete da Papelada apoia na elaboração de cartas para terceiros, currículos, cartões-de-visita, convites, envio e receção de e-mails, impressões e digitalizações. Este projeto conta com um número de beneficiários bastante elevado, sendo que o serviço começou por ser útil aos micaelenses mais idosos (nomeadamente os de mobilidade reduzida e com dificuldade no acesso aos transportes públicos e privados, para se deslocarem aos serviços centrais). Contudo, atualmente, os utentes mais novos, quando necessitam de resolver qualquer assunto burocrático, também já que procuram este serviço.

(iii) Gabinete do Desenrascanço Estudantil - O Gabinete do Desenrascanço Estudantil resultou da constatação dos elevados níveis de insucesso e abandono escolares, aquando da avaliação de necessidades da vila de São Miguel de Machede, no momento da constituição da Associação Suão. Nos anos 1999/2000 a população em idade escolar não possuía um projecto escolar/profissional a longo prazo, contribuindo para isso a baixa escolaridade das famílias e a falta de acesso a instrumentos motivadores de sucesso escolar e/ou valorização de conhecimentos académicos. O projeto permite proporcionar aos estudantes micaelenses iguais oportunidades de acesso e sucesso escolares. Para que o mesmo 
seja possível, o Gabinete tem parcerias como o IPDJ, o Centro Distrital de Évora da Segurança Social e o Agrupamento de Escolas n ${ }^{\circ} 4$ de Évora.

(iv) Biblioteca Comunitária -Na Biblioteca Comunitária existe um acero de, aproximadamente, 7 mil exemplares, distribuídos por diversas categorias. Este espaço pode ser utilizado por qualquer membro da população para atividades de leitura, pesquisa, realização de trabalhos escolares e utilização da internet. Com este espaço, pretende-se incentivar o hábito da leitura e da utilização das novas tecnologias da informação. A Suão conta com a parceria da Fundação Calouste Gulbenkian, neste projeto, desde 2009. Da calendarização de atividades constam a aquisição de fundo bibliográfico, preparação e execução de palestras e exposições, execução de boletins informativos e produção de materiais em suportes diversos.

(v) Serão do Sermão na Suão - O Serão do Sermão na Suão envolve a preparação e realização de palestras temáticas no mais variados domínios (social, cultural, educacional, ambiental, económica, desportiva e recreativa). Este projeto ocorre no auditório da Suão. Esta ação envolve meios técnicos e materiais como equipamento informático e audiovisuais; a elaboração e divulgação e divulgação das palestras. As parcerias são diversificadas, conforme as temáticas das palestras, sendo que podemos convidar diversas personalidades, interna ou externas à comunidade.

(vi) Andança da Suão - Esta ação contempla um conjunto de atividades que visam promover a Suão a nível nacional e internacional, através da participação em eventos formativos ou em encontros com outras instituições. Envolve a preparação de materiais que sejam expostos em locais ou eventos e deslocações da equipa técnica.

(vii) Circuito da Aldeia - O Circuito da Aldeia é um projeto comunitário que disponibiliza um produto de turismo pedagógico em meio rural, destinado a jovens urbanos e oriundos de contextos escolares ou institucionais, pessoas com necessidades educativas especiais e grupos de seniores institucionalizados. Este projeto criou e disponibilizou um roteiro de aprendizagem que contempla o contacto com as atividades e rotinas de uma pequena comunidade local rural, nas suas diversas circunstâncias vitais (economia, cultura, ambiente, desporto, instituições, famílias e pessoas) através de diferentes estações de aprendizagem (padaria, horta, adega, galinheiro, artesanato, jogos tradicionais, literatura tradicional, almoço familiar, percurso natural). O projeto proporciona o envolvimento da comunidade, combate o isolamento, 
promove o envelhecimento ativo, através da interação intergeracional e gera riqueza.

(viii) Visitas de Estudo - As visitas de estudo da Suão enquadram-se numa dinâmica educativa e sociocultural com interesse para a comunidade micaelense. Os beneficiários destas ações são toda a comunidade, visto todos podem participar, promovendo-se, assim, as relações intergeracionais. É de referir que o principal objetivo das visitas de estudo é dar, aos micaelenses, a possibilidade de conhecer o património cultural, histórico, geográfico e humano de Portugal.

(ix) Jornal Comunitário "Menino da Bica" - O Jornal Comunitário é produzido desde 1998, constituindo-se como um instrumento de participação e uma oportunidade de partilhar o que se sabe, o que se pensa e o que se faz no seio da comunidade micaelense. O objetivo é promover o gosto pela escrita e pela leitura, promover os saberes tradicionais, os pensamentos e as memórias comunitárias numa perspetiva de preservação da entidade comunitária e divulgar todas as atividades realizadas pela Suão ao longo do ano em questão. Os beneficiários são todos aqueles que têm acesso à informação disponibilizada (jornal em suporte papel ou através de divulgação online).

Todos os projetos mencionados foram, ao longo do tempo, alavancando recursos diversos, criando respostas adequadas às necessidades e ganhando novos contornos dependentes, também, das competências dos jovens que neles foram trabalhando no decurso de estágios profissionais, programas de voluntariado, presença nos órgãos sociais e recursos humanos da instituição.

As tecnologias de informação e comunicação foram estando cada vez mais presentes em todos os projetos e ações da Escola Comunitária, permitindo um entrelaçar de inovação e sustentabilidade, respeito pelo passado e necessidade responder aos desafios tecnológicos que nos ajudariam a alcançar o propósito da instituição: fazer chegar a mais pessoas e de modo mais eficiente a informação e os apoios disponibilizados.

\section{O CRESCIMENTO DOS PROJETOS E UMA NOVA FILEIRA DE OPORTUNIDADES}

Em todos os projetos, acima mencionados, conseguimos identificar a necessidade de acesso às tecnologias de informação e comunicação de modo a potenciá-las, quer na dimensão de crescimento do próprio projeto e sua divulgação, quer na dimensão de atuação com a comunidade. Um exemplo disso, foi a disponibilização, por parte da Suão, pela primeira vez, na vila de São Miguel de Machede de um computador com acesso à Internet para que os cidadãos pudessem navegar na rede. Estávamos 
em 1999, portanto, um projeto considerado inovador. Esse recurso tecnológico viria a instalar-se, e a transformar-se numa ferramenta essencial na comunicação e nas estratégias de trabalho.

Nos anos seguintes, a instituição adquiriu equipamento informático (computadores) que serviam, essencialmente, aos técnicos para consulta de materiais e artigos e aos alunos do Gabinete do Desenrascanço Estudantil, como apoio às pesquisas para trabalhos escolares e como modo de acesso a outras formas de divertimento virtual, visto que os jovens foram os primeiros a ter contacto com as novas tecnologias.

Em 2002, a Suão criou a sua página da internet para que, online, todos pudessem acompanhar o desenvolvimento dos projetos e atividades, oferecer sugestões e promover uma maior dinâmica na interação entre os utilizadores da internet.

Três anos mais tarde, em 2005, a Suão criou o primeiro Curso de Informática para Adultos. As aulas consistiam em aprendizagens na óptica do utilizador em programas como o Word, Power Point, Paint e utilização da internet, tendo por base projetos de grupo temáticos.

O Curso de Educação de Adultos integra, desde o seu início, as aulas de informática. As aulas são lecionadas por jovens voluntários e pelo quadro de recursos humanos da instituição que trazem à programação do curso novas ideias, mobilizando as competências de que cada um dispõe.

\section{A CRIAÇÃO DE UM GABINETE DE IMAGEM E COMUNICAÇÃO}

"A tecnologia tem impacto nas questões sociais, sobretudo na forma de pensar" (Alexandre Mars, fundador e CEO da Epic Foundation, Web Summit 2016)

Um investimento contínuo nas tecnologias de informação e comunicação e o acolhimento de jovens que necessitam de contextos reais de trabalho para promoverem as suas competências quer académicas, quer profissionais nestas áreas, permitiu a criação de um Gabinete de Imagem e Comunicação (GCI), no ano de 2017.

O jovem Flávio Ricardo Lino, residente em São Miguel de Machede, 21 anos e à data, a frequentar o Curso Profissional Técnico de Audiovisuais, no Agrupamento de Escolas $n^{\circ} 4$ de Évora, necessitava de realizar o seu trabalho final para conclusão do Curso. Estávamos no ano letivo 2015/2016. Para tal, contactou a associação, com o intuito de desenvolver um projeto que fosse ao encontro das necessidades da Suão e que permitisse utilizar os conhecimentos e ferramentas adquiridas, na área de educação e formação profissional referida.

Deste modo, procedeu-se à implementação do Gabinete de Imagem e Comunicação, com recurso a uma metodologia própria de trabalho, com reuniões de equipa, pesquisa e criação de materiais a utilizar, 
gravação de entrevistas e cenários, edição em vídeo e apresentação do vídeo (produto final) à população e online.

No GCI são produzidos conteúdos, em formato digital, de duração média de 30 minutos e com periocidade trimestral, relativos à realidade micaelense e que são divulgados nos seguintes meios: Serão do Sermão na Suão, página WEB e Facebook da Suão, canal Suão no youtube e o conteúdo é, ainda, enviado por correio eletrónico para os interessados e sócios.

O GCI pretende, assim, dar a conhecer, divulgar e valorizar a atividade da instituição; criar um instrumento acessível, participado e económico de comunicação entre todos os micaelenses; promover a partilha de conhecimentos e experiências entre todas as gerações micaelenses; conhecer, valorizar e divulgar o património material e imaterial da comunidade micaelense e promover a partilha de conhecimentos entre São Miguel de Machede e outras comunidades locais.

Este projeto deve, ainda, servir outros propósitos como é o caso de comunicação institucional que é um modo de partilhar a sua visão, valores e missão. Para a Suão, o GCI é uma ferramenta de comunicação com o exterior, alavancando o estabelecimento de parcerias e a comunicação com o público-alvo; cria a possibilidade de nos tornar mais visíveis o que pode ser muito pertinente no que diz respeito à criação de novas estratégias de trabalho.

\section{PERSPETIVAS FUTURAS}

O Gabinete de Imagem e Comunicação (GCI) pretende, num futuro próximo, realizar a partilha de conhecimentos, comunicação entre todos os micaelenses que residem dentro e fora de São Miguel de Machede, fazer chegar aos micaelenses informação mais regular dos acontecimentos sociais, culturais e festivos que se vão realizando em São Miguel de Machede.

Ainda que estes objetivos sirvam essencialmente a nossa comunidade, os conteúdos produzidos servem outros propósitos, constituindo-se, por isso, como materiais de trabalho, de divulgação e de ilustração do trabalho da instituição em congressos e/ou colóquios onde que participe.

O GCI é um projeto que torna a comunicação e o modo de trabalho mais transparente e eficaz, num compromisso com os valores da instituição e assumindo uma responsabilidade com o exterior, quer seja numa dimensão mais local/ comunitária, quer seja numa dimensão macro (regional e nacional).

"O que os empreendedores têm em comum não é determinado tipo de personalidade, mas umcompromisso com a prática sistemática da inovação." 


\section{(Peter Drucker, escritor, professor e consultor administrativo} de origem austríaca)

Resumo: A Escola Comunitária de São Miguel de Machede/Associação Suão, com início da sua atividade no ano de 1998, procurou, desde a sua fundação, "captar e aproveitar" as competências daqueles que, por algum motivo, se encontravam próximos de operacionalizar o objeto social desta Associação. Além disso, e por motivos de encaixe de competências adequadas à missão, os colaboradores da Associação Suão foram até ao momento, na sua maioria, jovens com formação na área da Educação e Ciências Sociais. Esta formação técnica é essencial para que os projetos comunitários sejam cientificamente tratados e possam ser mais eficazes, quanto ao alcance dos resultados pretendidos. Paralelamente a estes profissionais que tiveram uma oportunidade de emprego e/ou estágio foram sempre surgindo outras necessidades, quer de integração de jovens que mostraram interesse em colaborar com o grupo de trabalho, quer pela natural evolução da Associação, que exigiu a abertura a novas áreas do saber, como é o caso das tecnologias de informação e comunicação. $O$ crescimento dos projetos e a necessidade de os dar a conhecer aos potenciais utilizadores, tornando-os produtos sociais e comunitários de valor sustentável para a associação foram motivos mais que suficientes para um investimento humano e financeiro na área das tecnologias de informação. Esta nova fileira de trabalho é possível de ser implementada com a colaboração de jovens formados na área, a quem a Suão oferece ferramentas e conteúdos de trabalho e cuja oportunidade é um modo de valorização de competências e de crescimento pessoal para quem as trabalha. Assim, as tecnologias de informação e comunicação ganharam um duplo estatuto na Escola Comunitária de São Miguel de Machede, permitindo por um lado, acrescentar valor tecnológico aos projetos e tornaram-se elas próprios veículos de oportunidades para os jovens detentores destes conhecimentos, que conseguiram integrar-se através do seu uso, a favor da comunidade.

Palavras-chave: educação não formal, comunidade, projeto 
